Aquaculture

March 2006; 253(1-4) : 385-392

http://dx.doi.org/10.1016/j.aquaculture.2005.08.015

(C2005 Elsevier B.V. All rights reserved
Archimer, archive institutionnelle de l'Ifremer http://www.ifremer.fr/docelec/

\title{
Long-term monitoring of individual fish triggering activity on a self-feeding system: An example using European sea bass (Dicentrarchus labrax)
}

\author{
D. Covès ${ }^{a}$, M. Beauchaud ${ }^{b}$, J. Attia ${ }^{b}$, G. Dutto ${ }^{a}$, C. Bouchut ${ }^{b}$ and M.L. Bégout* \\ ${ }^{a}$ Station Expérimentale d'Aquaculture Ifremer, Laboratoire de Recherche Piscicole de Méditerranée, Chemin de \\ Maguelone, F-34250 Palavas-les-Flots, France \\ ${ }^{\mathrm{b}}$ Université Jean Monnet, Faculté des Sciences et Techniques, Laboratoire de Biologie Animale et Appliquée, 23 \\ rue du Dr. Paul Michelon, F-42023 Saint-Etienne Cedex 02, France \\ *: Corresponding author : Centre de Recherche sur les Ecosystèmes Marins et Aquacoles - UMR CNRS/Ifremer - \\ B.P. 5, F-17137 L'Houmeau, France. Tel.: +33 5465006 95; fax: +33 5465006 00. mlbegout@ifremer.fr
}

\begin{abstract}
In two experiments, a computerized on-demand feeding system coupled with a PIT tag monitoring device was used to continuously record the triggering activity by ca. 50 individual sea bass for 55 days (Exp. 1, initial average body weight and coefficient of variation, CV: $299 \mathrm{~g}, 15 \%$ ) and 69 days (Exp. 2, $157 \mathrm{~g}, 13 \%$ ). Each group was stocked in $1 \mathrm{m3}$ tanks and exposed to a water temperature of $21 \pm 1{ }^{\circ} \mathrm{C}$ and a light regime of 16:8 LD. Only $5 \%$ of the triggering activity was not associated with simultaneous PIT tag detection. Although each individual was detected via PIT tag during the experiment, only $67 \%$ and $74 \%$ of the fish actuated the trigger at least once in Exp. 1 and Exp. 2, respectively. Moreover, only two fish in Exp. 1 and one fish in Exp. 2 accounted for 82\% (43+ 39) and $77 \%$ of the total triggering activity, respectively. These three, high-triggering individuals did not exhibit a higher specific growth rate or agonistic behavior as observed by video monitoring. Indeed, zero-triggering fish had either a slightly higher SGR (Exp. 1) or a higher final body weight (Exp. 2) compared with low- and high-triggering fish.
\end{abstract}

Keywords: Sea bass; Self-feeding; Individual triggering activity; PIT tag detection antenna 


\section{Introduction}

In aquaculture there is a need to better understand feeding rhythms in order to facilitate a good match between the timing of feed distribution and fish biological rhythms. Further, feeding the fish at the appropriate time, may reduce feed wastage in aquaculture systems. To investigate feeding activity, there is a wide choice of methods from stomach content analysis, dyestuffs and markers, direct observation and video recording, on-demand feeder with feed waste monitor to XRay methods (reviewed in Jobling et al., 2001). Such methods either target group or individual feeding patterns for studies of feed preference, total feed intake measurement, feeding activity, and diel and seasonal feeding rhythms. Each of the methods has specific areas of application and each also has limitations (Jobling et al., 2001). There are difficulties involved in monitoring the feed intake of individuals within groups on a continuous basis over protracted time periods, and none of the methods cited addresses this problem satisfactorily. Nevertheless the potential for synergy between methods provides opportunities to increase our understanding of the influences various facets of fish behavior may have on feed intake, and in particular, how individual fish behaviors contribute to or are responsible for the resulting group behavior.

Extensive testing of different on-demand feeding systems for sea bass (Dicentrarchus labrax) (Covès et al. 1998, Rubio et al. 2004) has shown that this species demonstrates a great ability to use such systems and a high plasticity when facing the triggering device (pushing, pulling, biting) that could therefore be modified depending on the experimental objectives. Our research focused on individual fish trigger activity patterns : which fish were responsible for feed distribution for the group? The solution was found in the combination of two different methods: a computerized on-demand feeder and an individual PIT tag detector near the trigger (adaptation after Brännäs and Alanärä, 1993; Alanärä and Brännäs, 1996). The present paper illustrates the potential of that particular combination of techniques applied in the context of understanding how the dynamics of individual triggering behavior was related to group feeding (e.g. motivation, regime choices, rhythms) and individual growth in a marine cultured species. 


\subsection{Apparatus}

The device to operate the feeders comprised a screened type sensor (ST) (Covès et al. 1998, Rubio et al. 2004) and a control box. The ST sensor was a metal rod protected in a PVC cylinder surrounded by the PIT tag detection antenna (Fig. 1). The fish therefore had to enter horizontally through the PVC pipe, the PIT tag being detected at this time immediately prior to the activation of the rod. Individual triggering activity was counted continuously and stored every minute by a computer. Thus, PIT tag detection, rod triggering and feed distribution were recorded simultaneously through time. After each actuation fish were rewarded with pellets and feed dispensers were regulated to distribute $0.5-0.6 \mathrm{~g} \mathrm{~kg}^{-1}$ fish delivered $30 \mathrm{~cm}$ from the trigger. There was no blanking delay between switch actuations. The reward level (about 50-100 pellets each time, more than one per individual) was a compromise between minimizing wastage and optimizing feed allocation to the group. Such a set up allowed us to monitor two variables of interest : the individual feed demand and the group feed intake (because uneaten pellets were counted, see below). This device was realized by the contribution of two private French companies : Imetronic for the computerized self-feeding system and micro-BE for the PIT tag detection antenna.

Each individual fish was horizontally PIT-tagged by inserting a tag horizontally just behind the head to prevent any change of position subsequent to implantation (Fig. 1). Such horizontal positioning of the PIT tag allowed the best detection within the diameter $(10 \mathrm{~cm})$ of the antenna in accordance with the manufacturer's specifications requiring perpendicular plans. Behavioral investigations were undertaken by direct visual observation and video recording (CCD Panasonic WV BL 200 and Panasonic AG 6010). 


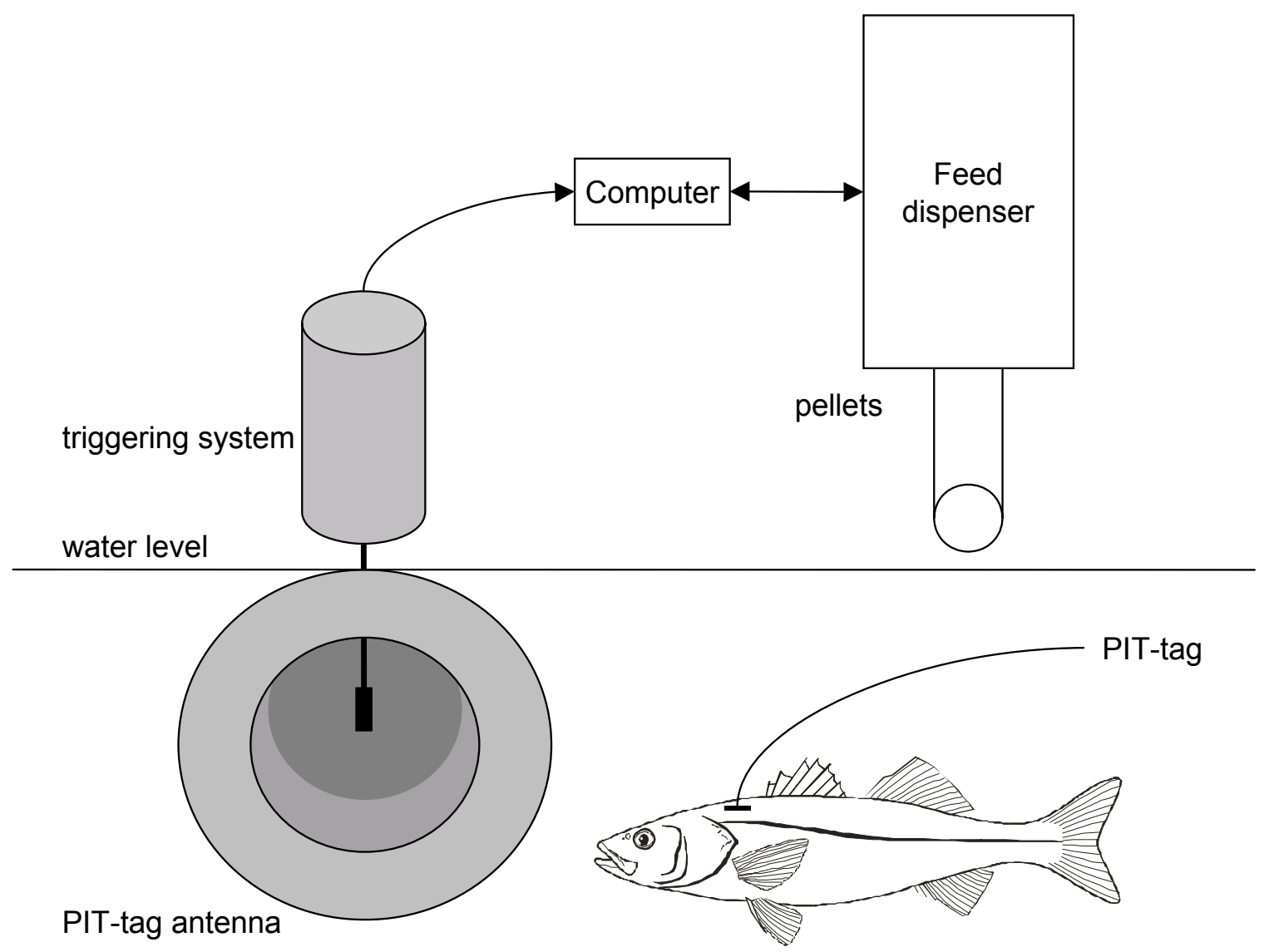

\subsection{Experimental set up}

The experiments were carried out with sea bass at IFREMER experimental station in Palavas (France). The tanks (described in Covès et al. 1998, Rubio et al. 2004) were supplied with sand filtered and UV-treated seawater (salinity 38\%, pH. 8) in a flow-through system (flow rate of $1 \mathrm{~m}^{3} \mathrm{~h}^{-1}$ in each tank). Water temperature was maintained at $21.0 \pm 1.0^{\circ} \mathrm{C}$ and oxygenated to maintain oxygen concentrations above $80 \%$ saturation in the outlet. Tanks were covered and a $75 \mathrm{~W}$ lamp was located about $70 \mathrm{~cm}$ above the water surface. Light regime was 16:8 LD (400 Lux: total darkness, light onset at 06:00 U.T. +1) with twilight transition periods of $30 \mathrm{~min}$. Fish were fed a commercial sea bass diet (SICA Le Gouessant, 29 Lamballe, France: 44\% crude protein, $22 \%$ lipid according to the manufacturer, 4 or $5 \mathrm{~mm}$ ). Feed hoppers were filled each day, 
and feed intake (quantity dispensed minus waste counted in the sediment trap) monitored daily during animal maintenance from 10:00 to 11:00 (U.T. +1) when triggering activity recordings were stopped for one hour. Both experiments were not replicated since they were methodological tests aimed at giving first results on a marine cultured fish species and at providing basic knowledge for future experiments.

\section{Experiment 1}

Experiment 1 (Exp. 1) was conducted with a group of 48 sea bass hatched and grown at the research station in Palavas. At the beginning of the study, fish were c. 30 mo. old with an average initial body weight (BWi) of $299 \mathrm{~g}$ (Coefficient of Variation $(\mathrm{CV})=15 \%, \mathrm{~N}=48$ fish). Fish were again weighed after 55 days of the experiment. Animals were placed under self-feeding conditions with feeders delivering $5 \mathrm{~mm}$ pellets. Food access was possible all day (24 h.) except during animal maintenance.

\section{Experiment 2}

Experiment 2 (Exp. 2) was conducted with a group of 49 sea bass hatched and grown at a fish farm (AEGAGROPILE, Marseillan, France). At the beginning of the experiment, the average initial body weight was $157 \mathrm{~g}(\mathrm{CV}=13 \%, \mathrm{~N}=49$ fish). Fish were weighed twice (after 22 days, 48 days) and at the end of the experiment (69 days). Animals were placed under selffeeding conditions with feeders delivering $4 \mathrm{~mm}$ pellets. Food access was possible all day (24 h.) except during animal maintenance. Among the group, 20 fish were excluded from growth statistical analysis because they were submitted to a tagging treatment on day 22 that did not impair their behavior but may have decreased their growth (Bégout Anras et al. 2003).

\subsection{Data analysis}

Initial coefficient of variation (CV) was calculated as: $100^{*} \mathrm{D}^{*} \mathrm{M}^{-1}$, where $\mathrm{D}$ is standard deviation of the individual weight and $M$ is average weight. The specific growth rate (SGR) was calculated using the following formula: SGR (\% body weight per day)=100(Ln BWf-Ln BWi)/N, where BWf and BWi are the final and initial body weight $(\mathrm{kg})$ respectively and $\mathrm{N}$ the total number of days. Average and standard deviation ( \pm SD) were calculated. Individual feed demand 
behavior (i.e. the number of trigger actuations per individual) was calculated and used to distinguish between high-triggering (> 30\% actuations), low-triggering $(0-30 \%)$ and zero-triggering $(0 \%)$ individuals. Triggering activity data was graphed as two dimensional plots to display the time series of individual demand activity in relation to time of day for the high-triggering fish in each experiment. The period length of rhythmic activity was determined by the concordogram method at a confidence level of $99 \%$ (Hassnaoui et al., 1998). Period was calculated using data on the whole population, including high and low-triggering fish, as well as on the high-triggering ones alone. A non-parametric statistical test (Kruskal-Wallis) was used to compare low- and hightriggering to zero-triggering fish differences in BWi, BWf and SGR.

\section{Results}

System reliability and fish agonistic behavior

The first step was to verify the functioning and accuracy of this computerized monitoring system. While $100 \%$ ID-code were recognized at least once in Exp. 1 and 2, $96.1 \%$ of the total number of registered actuations in Exp. 1 and $95.4 \%$ in Exp. 2 were paired with a corresponding ID-code registration. Direct or video observation confirmed the simultaneous activation of the PIT tag antenna and the triggering rod validating the usefulness of the method.

Further, video recording and visual observations showed that fish gently swam all around the tank with sub-groups of $4-5$ fish gathering for short periods of time close to the antenna area. Moreover, individuals did not compete for access to the triggering area and after each actuation, the whole fish population immediately congregated at the feeding point without demonstrating any agonistic behavior.

Individual fish classification

In Exp. 1, the first actuation occurred 9 days after the start of the experiment for all highand low-triggering fish. Two high-triggering individuals shared $82 \%$ of the total actuation number ( $43 \%$ for one and $39 \%$ for the other one, Fig. 2A). A group of 29 low-triggering individuals handled the rod for only $14 \%$ of the total actuations. The 17 remaining fish never actuated the trigger and were classified as zero-triggering individuals. 
In Exp. 2, the first actuation occurred only 6 days after the start of the experiment for all fish except the high-triggering individual that started triggering on day 11. For group 2, there was only one high-triggering fish responsible for $72 \%$ of the total actuations (Fig 2B). A group of 29 low-triggering individuals handled the trigger for only $23 \%$ of the total actuations. The 19 remaining fish never actuated the trigger and were classified as zero-triggering individuals.

Figure 2: Total actuation number in relation to fish individual ID code presented in a rank order. Some actuations were not coupled with the ID code registration (unexpl.), (a) Exp. 1 and (b) Exp. 2.

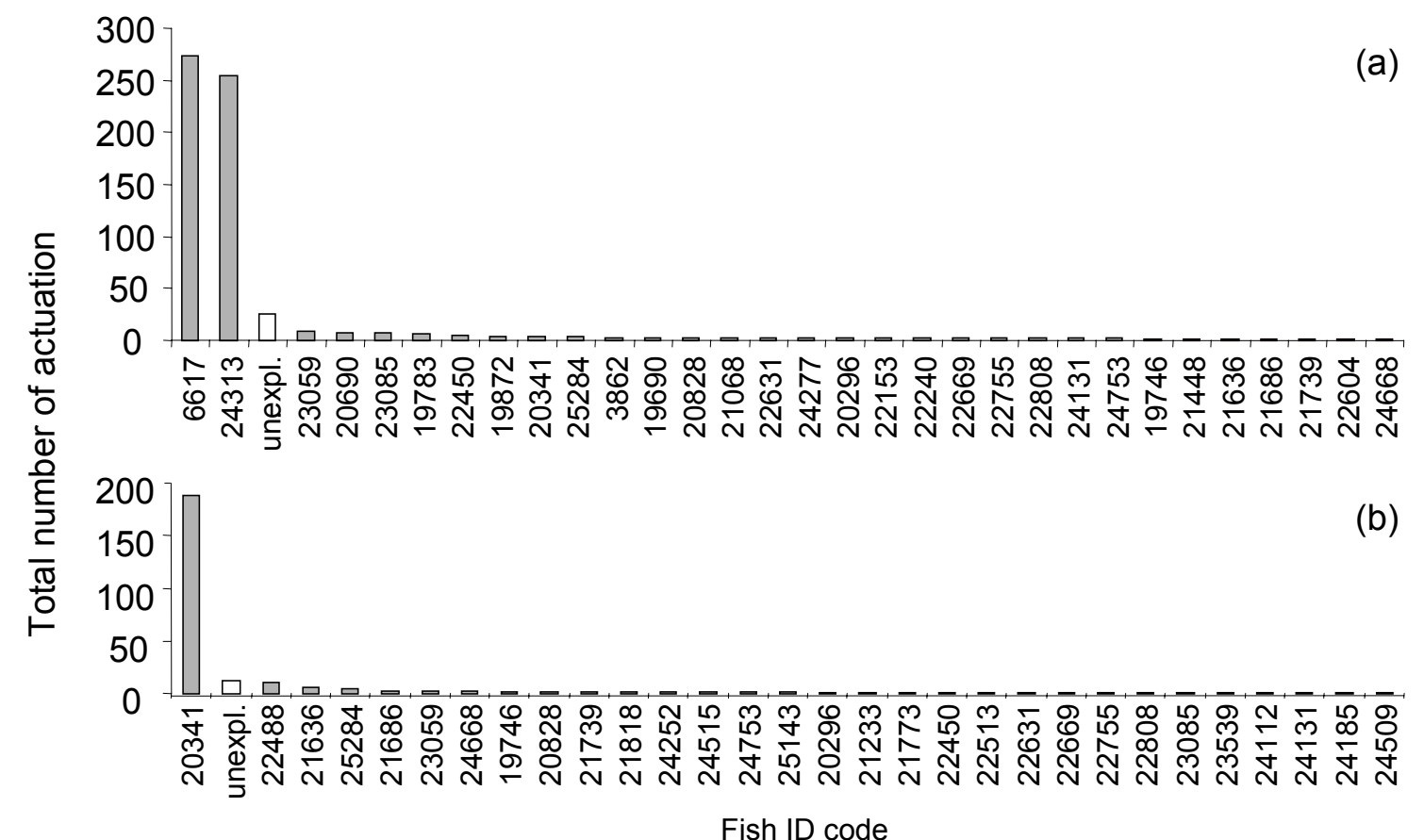

Rhythmic pattern of feed demand

In both experiments, high-triggering individuals showed very regular actuations during the experiment i.e. they did not stop triggering the rod for longer than 2 days (Exp. 1 illustrated, Fig. 3). However in Exp. 1, a particular temporal repartition was observed mostly at the beginning of the survey between the two high-triggering individuals: one was active at the beginning of the day while the other triggered the rod towards the end of the light phase (Fig. 3). 
Figure 3: Actogram of the two high-triggering fish of Exp. 1 from day 9 (D9) to day 52 (D52). Triggering activity was summed up per hour and each shaded square represents one hour when at least one fish activated the trigger one time. Dark gray square: triggering activity of high-triggering fish $n^{\circ} 1$. Light gray square: triggering activity of high-triggering fish $\mathrm{n}^{\circ} 2$. Black square: both high-triggering fish activated the trigger during the same hour. Bottom dark bars indicate dark phase.

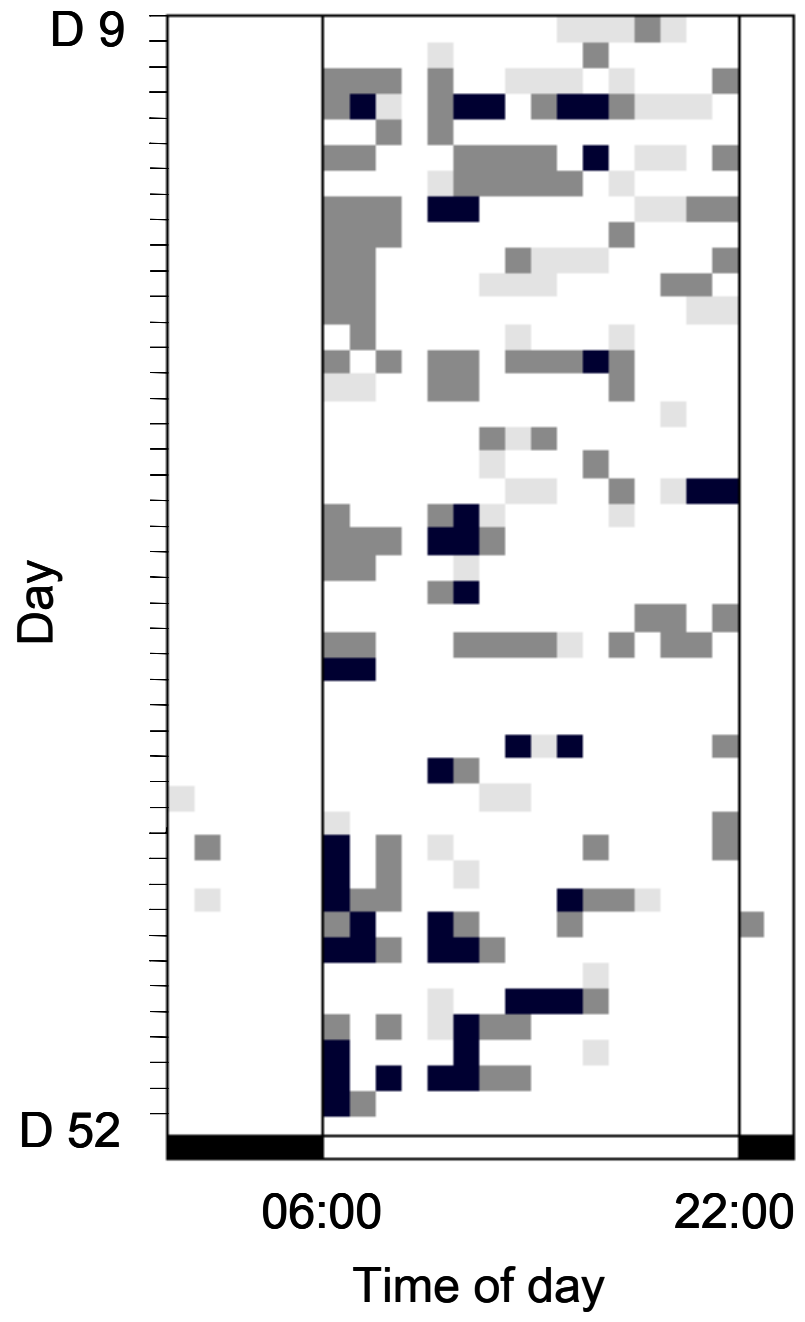

In both experiments, the mean daily profiles of triggering activity of the whole population was largely explained by the profile of the high-triggering fish (Exp. 1: $R^{2}=0.80, P<0.001$; Exp. 2 : $\mathrm{R}^{2}=0.84, \mathrm{P}<0.001$ ), (Fig. 4a). The demand pattern of the low-triggering fish could be considered as background noise. Almost all the triggering activity occurred during the light phase in both experiments. In the two high-triggering fish of Exp. 1, the mean daily profiles showed an increase of activity at dawn and then a gradual decrease until dusk (Fig. 4a). In Exp. 2, the pattern of triggering activity in the high-triggering fish showed a clear major peak at dawn (Fig. 4a). 
The concordance method detected a $24 \mathrm{~h}$ period both for the population and the high-triggering fish (Fig. 4b). The very low activity on the rod of low-triggering fish did not allow us to detect any period.

Figure 4: (a) Mean triggering activity per hour $\left(\mathrm{A} \mathrm{h}^{-1}\right.$, with $\mathrm{A}=$ number of actuations) over the $24 \mathrm{~h}$ cycle for Exp. 1 and Exp. 2. Legend: black line for high and low-triggering fish, dashed and gray line for high-triggering individual, bottom dashed line for low-triggering fish only. Grey rectangles represent dark phase and dotted rectangle animal care period without recordings. (b) Concordogram calculated on the time series of triggering activity for high-triggering fish $n^{\circ} 1$ in Exp. 1 and the high-triggering fish of Exp. 2.
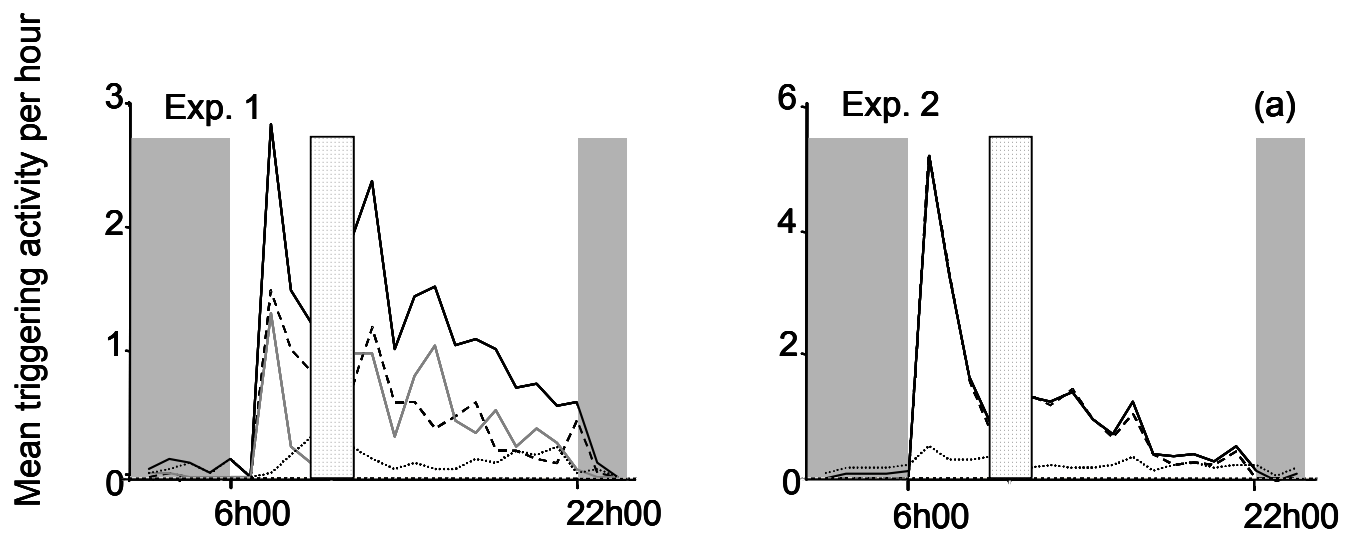

Exp. 1

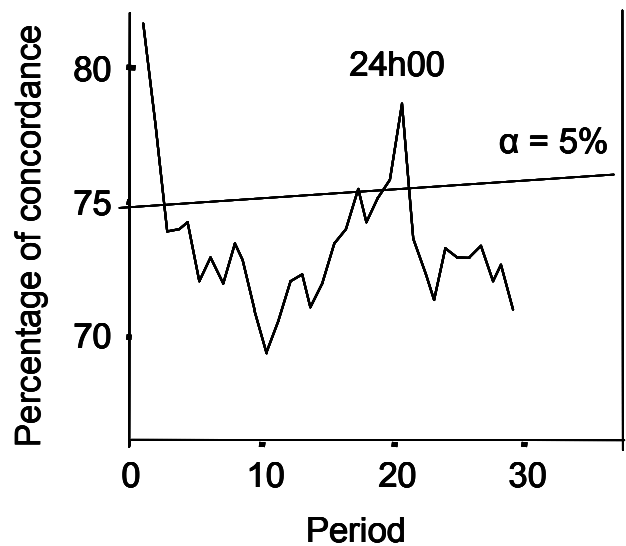

Exp. 2

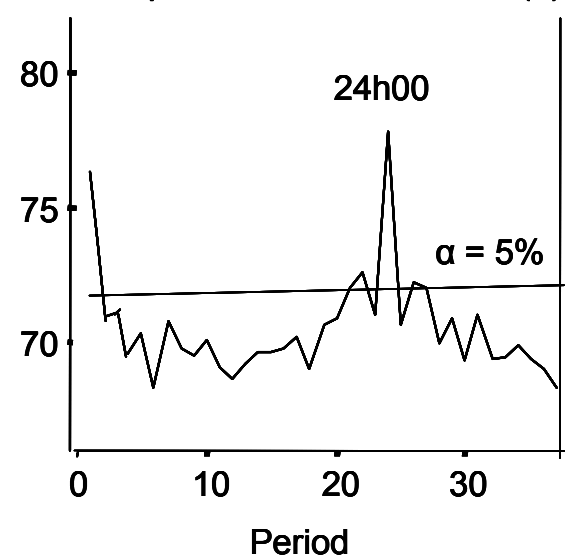

Fish growth

Under our experimental conditions, the average SGR was among expected values for that fish size. Indeed for Exp. 1, average SGR was $0.59 \% \pm 0.11( \pm S D)$ and for Exp. 2, average SGR was $0.82 \% \pm 0.14$. It should be noted that uneaten feed was nil and therefore high rates of individual triggering were associated with high rates of group feeding. 
At the individual level, in Exp. 1, the high-triggering fish, both males, belonged to the smallest or to the biggest initial body weight fish group respectively (Fig. 5). They displayed SGR (0.61 and $0.57 \%$ ) similar to population average and maintained the same weight rank until the end of the experiment. No differences in BWi and BWf were observed between triggering (low- and high-) and zero-triggering fish $\left(\mathrm{KW}_{(\mathrm{Bwi})}=257, \mathrm{P}=0.97 ; \mathrm{KW}_{(\mathrm{BWf})}=265, \mathrm{P}=0.84\right.$ with $\left.\mathrm{N}=48, \mathrm{df}=1\right)$. However, a statistical difference was observed for $S G R\left(K W_{(S G R)}=360, P=0.02\right.$ with $N=48$, df=1) with zerotriggering fish showing the higher SGR of $0.62 \% \pm 0.10$ compared to $0.57 \% \pm 0.11$ for low- and high-triggering fish.

In Exp. 2, the high-triggering fish was one of the 2 females of the group. This individual displayed one of the highest SGR $(0.97 \%)$. No differences in BWi were observed between triggering (lowand high-) and zero-triggering fish $\left(\mathrm{KW}_{(\mathrm{Bwi})}=101, \mathrm{P}=0.22\right.$ with $\left.\mathrm{N}=29, \mathrm{df}=1\right)$ but fish differed in $\mathrm{BWf}$ $\left(\mathrm{KW}_{(\mathrm{BWf})}=118, \mathrm{P}=0.04\right.$ with $\left.\mathrm{N}=29, \mathrm{df}=1\right)$ and zero-triggering fish showed a higher BWf of $279.7 \mathrm{~g} \pm 40.1$ compared to $245.2 \mathrm{~g} \pm 38.6$ for low and high-triggering fish. In that experiment, no difference was observed for $S G R\left(K W_{(S G R)}=98, P=0.28\right.$ with $N=29$, $\left.d f=1\right)$.
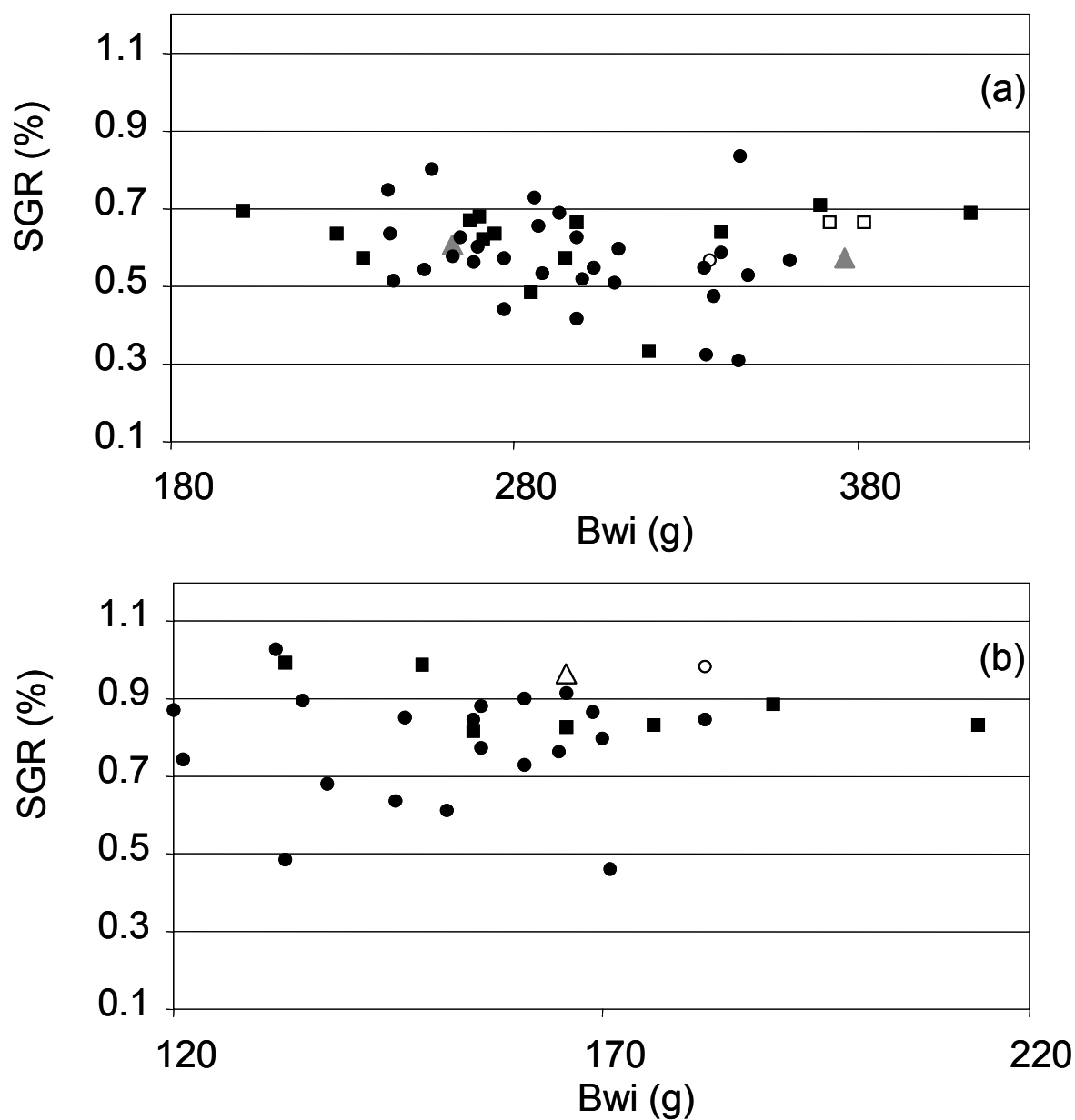


\section{Discussion}

Results of this study demonstrated the accuracy of the apparatus, and underscored the similarities and peculiarities of individual sea bass triggering patterns compared with studies on other species.

\section{Accuracy of feeding demand registration device}

The monitoring system designed for this test seemed efficient since $95 \%$ of registered actuations were paired with an ID-code registration. Alanärä and Brännäs (1993) proposed the hypothesis that missed ID-readings could be attributed to the decreased recording accuracy associated with PIT tags injected obliquely. Also, according to the same authors, ID-codes may have failed to be registered on occasion when fish attacked the trigger from an oblique angle. However, in our device, this hypothesis failed because the respective position of the antenna and the trigger prevented an oblique attack but we noticed that PIT tag detection did not work when two individuals were within the antenna.

\section{Feed demand activity}

Sea bass used in the experiments were naive to the self-feeding apparatus, with triggering activity starting 6-9 days after the start of the experiment. Such a delay is known to vary greatly according to the apparatus design (Rubio et al., 2004) and species. It likely corresponds to a learning phase and sea bass is described as having a high learning potential including associative learning abilities (Rubio et al., 2003).

Our results showed that within a group of about 50 sea bass, only one or two animals are responsible for $80 \%$ of the triggering activity under a reward regime of 1 or 2 pellets per individual given after each actuation. The rest of the population could be divided in two groups: individuals that seldom actuated the trigger and fish that never actuated the device. Such a classification was not surprising since Alanärä and Brännäs (1993) and Brännäs and Alanärä (1993) demonstrated such behavioral structure in salmonids. They identified 3 levels of triggering activity and ranked fish as dominant, sub-dominants and subordinates. In their studies, they showed that social rank was directly correlated with self-feeding device triggering: dominant fish 
had the higher actuation level, sub-dominants and subordinates showed respectively the medium and lowest actuation level. In Arctic char a link with brain serotonergic activity and social status was also confirmed within a dominance hierarchy (Alanärä et al., 1998). However, in salmonids, the demand feeders were predominantly monopolized by the highest-ranked fish with dominant fish having preferential access to delivered feed resulting in a higher SGR compared to other fish in the tank. In our study, direct and video observations did not show any differential access to delivered feed nor did high-triggering sea bass monopolize the trigger and distributed pellets but indeed zero-triggering fish showed a slightly better final weight or SGR. This is in accordance with another study (Chen et al., 2002) that showed that SGR was not always higher for dominant fish. However, McCarthy et al. (1992) underscored that preferential access still often existed. Further, under a hierarchical situation, agonistic behavior occurred on a regular basis (Johnsson and Akerman, 1998 ; Heuts and Nijman, 1998). In relation to spatial distribution, dominant fish tended to occupy a larger space than sub-dominant or subordinates and stayed outside the group. Such behavior was observed for trout (Alanärä, 1992 a, b) and black bass (Petit et al., 2003).

Under our rather low density $\left(20 \mathrm{~kg} \mathrm{~m}^{-3}\right)$ experimental conditions, agonistic behavior (biting, scale loss or fin damage) was not observed. Further, space usage appeared similar for all individuals. Therefore, we hypothesized that good SGR were achieved because feed access was homogeneous among all fish and they received a sufficient ration with little or no social interactions that could be linked to the low density (Brown et al., 1992). For these reasons, we would not use the terms "dominant" / "subordinates" for sea bass behavioral classification proposing instead a more descriptive terminology : high-triggering, low-triggering and zerotriggering fish.

In general, fish feed intake patterns vary mostly in relation to photoperiod and temperature (Madrid et al., 2001). At the beginning of our study, the two high-triggering fish in Exp. 1, shared the triggering activity in time: one being active in the dawn and morning and the other one in the afternoon and dusk period. Such temporal partitioning could result from social interactions between those two high-triggering fish. Therefore, the patterns observed would depend on both abiotic factors (photoperiod) and biotic factors (social interactions, or even competition) as shown for trout (Chen et al, 2002). Further, we can note that the total number of 
trigger actuation was similar for both experiments although there was only one or two hightriggering fish controlling pellet delivery. Because non-ingested food was nil, we could be sure that all distributed feed was actually ingested by the group in both experiments resulting in good SGR. Given such parameters, on one hand, it is interesting to note that the feed distribution and thus, high-triggering fish activity, seemed to be adjusted to the group needs rather maybe than to the individual's needs. On the other hand, high-triggering individuals didn't gain particular benefit from their triggering ability.

These results suggest that in physiological or nutrition studies such as macronutrient selection carried out under self-feeding conditions, behavioral categorization of individuals should be considered. Indeed, if the high-triggering fish are removed, either when fish are randomly distributed among tanks or when destructive sampling is used, the consequences to the fish group when such population structure changes take place should be taken into account. One can envision several ways to employ this technology in future experiments investigating aspects of feeding behavior e.g. feeding motivation and social organization in relation to environmental factors or stressors, and attempting to increasing the efficiency of aquaculture.

\section{Acknowledgements}

We wish to thank C. Darracq (Imetronic), S. Ternoir and M. Snoussi (MicroBE) for their support in technological developments. An earlier version of this work was presented at the final workshop of the COST Action 827 "Regulation of voluntary feed intake in fish" held in Reykjavik, 16-18 August 2001. This work was performed within the Integrated Research Project SEAFOODplus, contract No FOOD-CT-2004-506359. The partial financing of the work by the European Union is gratefully acknowledged.

\section{References}

Alanärä, A., 1992a. Demand feeding as a self-regulating system for rainbow trout (Oncorhynchus mykiss) in net-pens. Aquaculture 108, 347-356

Alanärä, A., 1992b. The effect of time-restricted demand feeding on feeding activity, growth and feed conversion in rainbow trout (Oncorhynchus mykiss). Aquaculture 108, 357-368. 
Alanärä, A., Brännäs, E., 1993. A test of the individual feeding activity and food size preference in rainbow trout using demand feeders. Aquac. Int. 1, 47-54.

Alanärä, A., Brännäs, E., 1996. Dominance in demand-feeding behaviour in Arctic charr and rainbow trout: The effect of stocking density. J. Fish Biol. 48, 242-254.

Alanärä, A., Winberg, S., Brännäs, E., Kiessling, A., Höglund, E., Elofsson, U., 1998. Feeding behaviour, brain serotonergic activity levels, and energy reserves of Artic char (Salvelinus alpinus) within a dominance hierarchy. Can. J. Zool. 76, 212-220.

Bégout Anras, M.L., Covès, D., Dutto, G., Laffargue, P., Lagardère, F., 2003. Tagging juvenile seabass and sole with telemetry transmitters: medium-term effects on growth. ICES J. mar. Sci. $60,1328-1334$.

Brännäs, E., Alanärä, A., 1993. Monitoring the demand feeding activity of individual fish with a demand feeding system. J. Fish Biol. 42, 209-215.

Brown, G.E., Brown, J.A., Srivastava, R.K., 1992. The effect of stocking density on the behaviour of arctic charr (Salvenius alpinus L.). J. Fish Biol. 41, 955-963.

Chen, W.-M., Naruse, M., Tabata, M., 2002. The effect of social interactions on circadian selffeeding rhythms in rainbow trout Oncorhynchus mykiss Walbaum. Physiology \& Behavior 76, 281-287.

Covès, D., Gasset, E., Lemarié, G., Dutto, G., 1998. A simple way of avoiding feed wastage in European seabass, Dicentrachus labrax, under self-feeding conditions. Aquat. Living Resour. $11,395-401$.

Hassnaoui, M., Pupier, R., Attia, J., Blanc, A., Beauchaud, M., Buisson, B., 1998. Some tools to analyse changes of rhythms in biological time series. Biological Rhythm Research 29, 353366.

Heuts, B.A., Nijman, V., 1998. Agressive behaviour of two swordtail colour breed (Xiphophorus, Poecilidea) in a prior residence situation. Behav. Process 43, 251-255.

Jobling, M;, Covès, D., Damsgård, B., Kristiansen, H.R., Koskela, J., Petursdottir, T.E., Kadri, S., Gudmundsson, O., 2001. Techniques for measuring feed intake. In Houlihan, D., Boujard, T., Jobling, M. (Eds), Food Intake in Fish. Blackwell Science Ltd, Oxford, pp. 49-87.

Johnsson, J.I., Åkerman, A., 1998. Watch and learn: preview of the fighting ability of opponents alters contest behaviour in rainbow trout. Anim. Behav. 56, 771-776. 
Madrid, J.A., Boujard, T., Sanchez-Vazquez, F.J., 2001. Feeding Rhythms. In Houlihan, D., Boujard, T., Jobling, M. (Eds), Food Intake in Fish. Blackwell Science Ltd, Oxford, pp. 189215.

McCarthy, I.D., Carter, C.G., Houlihan, D.F., 1992. The effect of feeding hierarchy on individual variability in daily feeding of rainbow trout, Oncorhynchus mykiss (Walbaum). J. Fish Biol. 41, 257-263.

Petit, G., Beauchaud, M., Attia, J., Buisson, B., 2003. Food intake and growth of largemouth bass (Micropterus salmoides) held under alternated light/dark cycle (12L:12D) or exposed to continuous light. Aquaculture 228, 397-401.

Rubio, V.C., Sanchez-Vazquez, F.J., Madrid, J.A., 2003. Macronutrient selection through postingestive signals in sea bass fed on gelatine capsules. Physiology \& Behavior 78, 795803.

Rubio, V.C., Vivas, M., Sanchez-Mut, A., Sanchez-Vazquez, F.J., Covès, D., Dutto, G., Madrid, J.A., 2004. Self-feeding of European sea bass (Dicentrarchus labrax, L.) under laboratory and farming conditions using a string sensor. Aquaculture 233, 393-403. 